\title{
1983 PROGRAM CHAIRMEN
}

The Society's 1983 Annual Meeting already is being planned. The three scientists who will be responsible for its content represent a cross-section of the Society's diversity, background

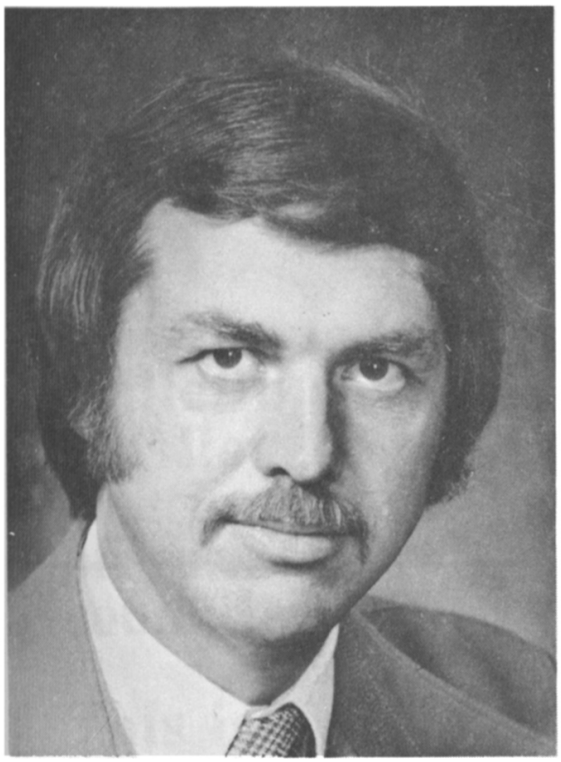

B. R. APPLETON P. O. Box X Oak Ridge National Laboratory Oak Ridge, TN 37830 (615) 574-6283

After undergraduate study at the University of Missouri, Appleton took his $\mathrm{Ph}$. D. in physics from Rutgers in 1966.

Appleton's current research interests include ion-solid interactions, radiation damage mechanisms, materials properties, surface studies by ion scatteringchanneling, and alteration of materials properties by ion implantation doping, ion beam mixing and laser annealing of ionimplanted materials. $\mathrm{He}$ also is interested in corrosion phenomena, superconducting properties and amorphous transitions in metals by ion implantation and laser annealing.

Long active in scientific affairs, Appleton is Editor of Applications of Applied Nuclear Science, a former co-chairman of the MRS Symposium on Laser and Electron Beam Interactions with Solids, and is currently a member of the Society's Nominating Committee. and current research interests. As they begin to organize the symposia and other events that will occupy us next year, every MRS member is encouraged to forward his or her

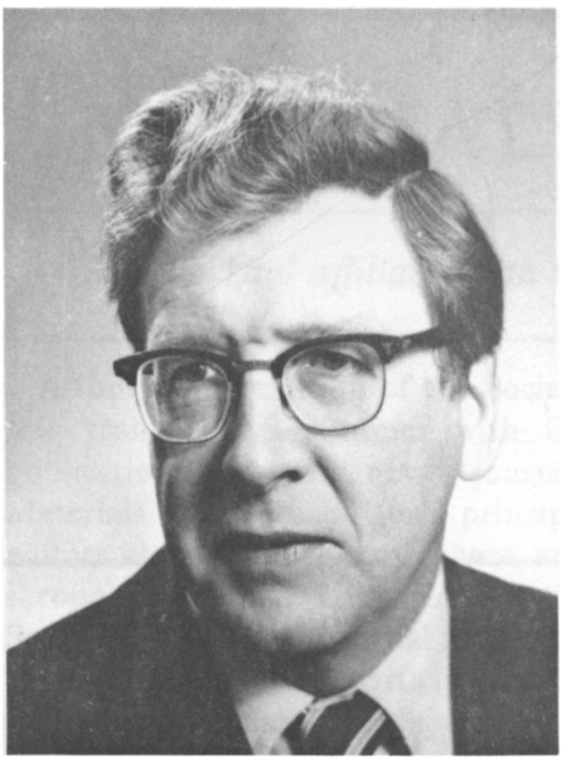

BERNARD H. KEAR Exxon Research and Engineering

Center P. O. Box 45 Linden, NJ 07036 (201) 474-6393

A native of Wales, Kear holds in addition to the $\mathrm{Ph}$. D. the $\mathrm{D}$. Sc., granted in 1970 by the University of Birmingham, England.

At Exxon he is most intimately involved in research on rapid solidification of materials using directed energy beams, but his current interests also embrace the structure and properties of ordered and high-temperature alloys, dislocation theory as applied to superlattices, laser-materials interactions and other subjects.

Author of 115 technical publications and editor of four technical books, Kear holds 19 patents. $\mathrm{He}$ was awarded the Mathewson Gold Medal of TMSAIME in 1971 and the Howe Medal of ASM in 1970, which admitted him as a Fellow in 1976. Listed in Who's Who in America and Who'S Who in Engineering, Kear delivered the John Dorn Memorial Lecture in 1980. suggestions for possible topics to be explored at the meeting to them at the addresses indicated.

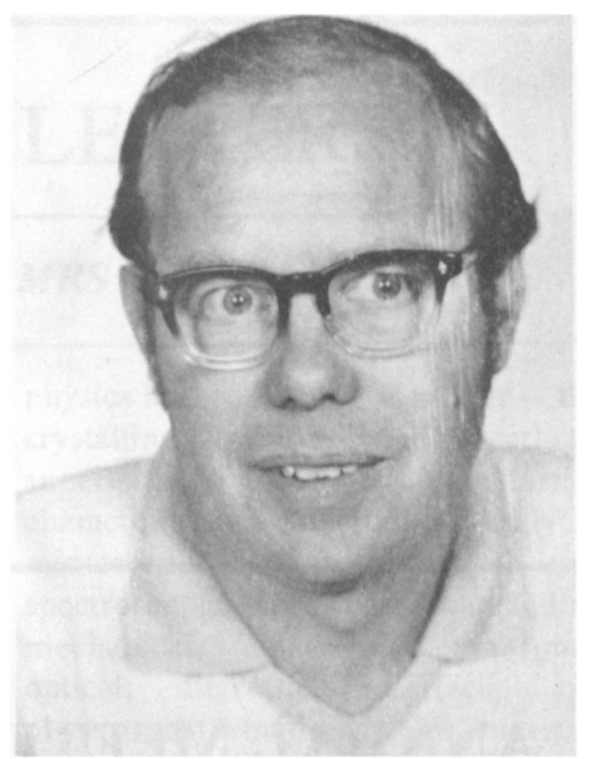

GORDON PIKE Sandia National Laboratories Albuquerque, NM 87185 (505) 844-9168

Pike received his undergraduate degree in physics from CarnegieMellon University and his $\mathrm{Ph}$. D., also in physics, from the University of Pittsburgh in 1969.

He joined Sandia National Laboratories, where he has conducted experimental research in superconductivity, ac conductivity of insulators, metal-semiconductor contacts, electronic and mass transport in inhomogeneous materials, and radiation effects in MOSFET transistors.

An organizer of the 1981 MRS Symposium on Semiconductor Grain Boundaries, Pike edited the proceedings of that symposium. He also served as chairman of the Symposium on Semiconductor Grain Boundaries of the March 1982 meeting of the American Physical Society. From 1979 to the present, he has represented the APS in its Visiting Physicist Program at universities. 